\title{
Patient Delay and Contributing Factors Among Breast Cancer Patients at Two Cancer Referral Centres in Ethiopia: A Cross-Sectional Study
}

This article was published in the following Dove Press journal: Journal of Multidisciplinary Healthcare

\author{
Aragaw Tesfaw $\mathbb{D}^{1}$ \\ Solomon Demis ${ }^{2}$ \\ Tigabu Munye ${ }^{3}$ \\ Zemachu Ashuro (iD) ${ }^{4}$ \\ 'Department of Public Health, Debre \\ Tabor University, College of Health \\ Sciences, Debre Tabor, Ethiopia; \\ ${ }^{2}$ Department of Pediatrics and neonatal \\ Nursing, Debre Tabor University, College \\ of Health Sciences, Debre Tabor, \\ Ethiopia; ${ }^{3}$ Department of Comprehensive \\ Nursing, Debre Tabor University, College \\ of Health Sciences, Debre Tabor, \\ Ethiopia; ${ }^{4}$ Dilla University, College of \\ Health Sciences, Dilla, Southern Ethiopia
}

Background: Unlike developed countries, there is high mortality of breast cancer in lowand middle-income countries associated with prolonged patient delays and advanced stage presentations. However, evidence-based information about patient delay in presentation and contributing factors to diagnosis of breast cancer in Ethiopia is scarce.

Methods: Institution-based cross-sectional study was conducted at oncology units of the University of Gondar and Felege Hiwot specialized hospitals. A total of 371 female breast cancer patients who were newly diagnosed from September 2019 to April 30, 2020 were included. Data were entered using EPI info version 7.2 and analyzed in SPSS version 23. Descriptive statistics was used to summarize socio-demographic and clinical characteristic of the patients. Multivariable logistic regression at a $P$-value $<0.05$ significance level was used to identify predictors of patient delay.

Results: A total of 281 ( $75.7 \%$ ) patients had long patient delay of $\geq 90$ days ( 3 months) with the average patient delay time of 8 months, and advanced stage diagnosis was found on $264(71.2 \%)$ of patients. The median age of patients was 40 years. Rural residence (AOR $=3.72 ; 95 \%$ $\mathrm{CI}=1.82-7.61)$, illiterate $(\mathrm{AOR}=3.8 ; 95 \% \mathrm{CI}=1.71-8.64)$, having a painless wound $(\mathrm{AOR}=3.32$; $95 \% \mathrm{CI}=1.93,5.72)$, travel distance $\geq 5 \mathrm{~km}(\mathrm{AOR}=1.66 ; 95 \% \mathrm{CI}=1.09-3.00)$, having no lump/ swelling in the armpit $(\mathrm{AOR}=6.16 ; 95 \% \mathrm{CI}=2.80-13.54)$, and no history of any breast problem before $(\mathrm{AOR}=2.46 ; 95 \% \mathrm{CI}=(1.43-4.22)$ were predictors for long patient delay.

Conclusion: Long patient delay and advanced stage diagnosis of breast cancer are higher in our study. Travel distance $\geq 5 \mathrm{~km}$, rural residence, no history of any breast problem before, having no lump/swelling in the arm pit, a painless lump in the breast, and being illiterate were important predictors for patient delay. Therefore, public awareness programs about breast cancer should be designed to prevent patient delay in presentation and to promote early detection of cases before advancement.

Keywords: breast cancer, patient delay, predictors, Ethiopia

\section{Background}

Cancer is a major non-communicable disease with high global public health burden globally. It is the third leading cause of death in low- and middle-income countries. ${ }^{1}$ Breast cancer is one of the most frequently diagnosed cancers, which affects mostly women. ${ }^{2}$ The mortality statistics showthat Africa had the highest breast cancer mortality rate in the world and rising incidence of the disease. ${ }^{3}$ Almost half of breast cancer cases and deaths occur in low- and middle-income countries (LMICs). ${ }^{4}$
Correspondence: Aragaw Tesfaw Debre Tabor University, College of Health Science Department of Public Health, PO Box 272, Debre Tabor, Ethiopia

Tel +251921743820

Email aragetesfa05@gmail.com
Journal of Multidisciplinary Healthcare 2020:13 |39|-|40| 
The incidence of new breast cancer cases in Ethiopia is now increasing and it has become the most prevalent tumor among women with an estimated incidence rate of 43 cases per 100,000 women. According to the national cancer registry report, breast cancer accounts for $30.2 \%$ of all cancer cases in the country with an upward increase in trend. ${ }^{5,6}$

Despite the rising burden of breast cancer cases globally, delayed diagnosis and late stage presentation are common problems, particularly in low- and middleincome countries. ${ }^{7}$ Although early diagnosis of breast cancer results in improvements in survival and mortality from the disease, many health systems in low- and middleincome countries faced challenges to manage the burden due to little community awareness and poor diagnostic and treatment services. ${ }^{8,9}$

The major contributing factor mentioned for advanced stage diagnosis in developing countries is delayed presentation to health facilities after the disease has progressed. However, breast cancer is often diagnosed at an early stage and the prognosis is good in high-income countries. ${ }^{7,10}$

A study conducted in urban South Africa found that the most common stage among breast cancer patients was Stage 3 (55\%), and T4 tumor (30.5\%). ${ }^{11}$ Similarly a study in Nigeria reported that $67.3 \%$ of breast cancer patients were diagnosed at advanced stage and $76.4 \%$ had invasive ductal carcinoma. ${ }^{12}$

Several factors have been found to contribute to a delay in diagnosis of breast cancer which are either from patients or healthcare related factors. Two systematic reviews in Africa revealed that lack of knowledge, negative symptom interpretation, beliefs in traditional medicine, lack of trust and access in healthcare were some of the factors for patient delay in the diagnosis of breast cancer among African women. ${ }^{13,14}$ The average times between symptom recognition and presentation to a healthcare provider ranged from less than 3 to greater than 6 months in sub-Saharan Africa. Some of the reasons mentioned for patient delay in presentation were low educational level, lack of breast cancer awareness, and poor knowledge of early-detection methods, type of initial symptoms: painless, not taken seriously, or hoping they would resolve soon, fear of the disease and its treatment (eg, mastectomy) or death, or of being a burden to the family, belief in traditional medicine or spiritual cures; financial constraints; and poor access to healthcare. ${ }^{15}$

A study in China found that the range of patient delay was $0.2-900$ days, with a median patient delay of 50 days. A total of $35.8 \%$ of patients waited $\geq 90$ days to access medical treatment after symptom onset. The study showed that the main predictors of patient delay were knowledge of breast cancer symptoms, breast self-examination/physical examination, perceived health competence, family support, pain stimulation, and age. ${ }^{16}$

A meta-analysis in Africa found the overall summary estimate of late presentation ( $>90$ days) was $54 \%$ and was worst in the eastern and central regions. Symptom misinterpretation $(50 \%)$ followed by fear $(17 \%)$, preference for alternative care $(10 \%)$, and social influence were the major factors for patient delay. ${ }^{17}$ There are limited oncology centers in Ethiopia with only one radiotherapy center to serve more than 100 million population of the country, which is inaccessible to the majority of the rural population. The main focus of the government and healthcare systems were towards other infectious diseases than cancer until recent years. As a result, the majority of reported cases of breast cancer have delayed presentations and most of the patients have an incurable disease. ${ }^{18,19}$

However the magnitude and factors contributing to patient delay for presentation to a healthcare facility on breast cancer remains an area where strong evidence is lacking in the country in general and the region in particular, since some of the available reports are based on the only oncology and radiotherapy center at Addis Ababa, which may not be representative of the majority of the rural population. In addition, the factors for patient delay in presentation vary from region-to-region depending on the socio-cultural and healthcare system differences. Therefore this study was aimed to assess patient delay and contributing factors among breast cancer patients diagnosed at the only two oncology referral centers in Amhara region, North-western Ethiopia.

\section{Methods}

\section{Study Design, Area, and Population}

This study was an institution based cross-sectional study carried out in the two oncology centers (Felege Hiwot, and University of Gondar specialized hospitals) in Northwest Ethiopia from September 2019 to April, 30 2020. The hospitals are used as the only oncology referral centers for all cancer cases, including breast cancer in the Amhara Regional State, Ethiopia. Felege Hiwot referral hospital is found in Bahirdar city $565 \mathrm{~km}$ from Addis Ababa (the capital city of Ethiopia). The hospital serves more than 10 million people in its catchment area and is used as a teaching hospital for medical and health science 
students. The hospital currently provides diagnostic, surgical, and chemotherapy treatment services for cancer patients, including breast cancer.

University of Gondar hospital is a comprehensive specialized and teaching hospital found $737 \mathrm{~km}$ from the capital city of Ethiopia (Addis Ababa). More than 450,000 people visit the hospital every year for different health services. It is a 400-bed university hospital and serves a population of more than seven million across the region. The hospital has a separate oncology unit which provides diagnostics, treatment, and palliative care for breast cancer patients referred from different corners of the region. As a university hospital, it plays an important role in teaching medical and other health science students in different streams and specialities including oncology. The hospital also refers cases to Addis Ababa for radiotherapy after initial treatment.

\section{Sample Size, Measurements, and Data Collection Procedures}

The study subjects were all breast cancer patients' newly diagnosed from September 2019 to April 30, 2020 at the selected hospitals. All breast patients who had pathologically confirmed breast cancer were included in the study. The data was collected using structured and pre-tested questionnaires which were developed after a review of relevant literature and other materials that can address the objectives of the study. ${ }^{15,20-22}$ The questionnaire was prepared in the English version and translated to the local language (Amharic) to facilitate communication. The components of the questionnaires were introductory and demographic information, patient's history on diagnostic pathway, medical and family history, dates of all important time points (eg, first symptom discovery until first healthcare contact and other behavioral factors of the patients. Information on stage at diagnosis and tumor characteristics was collected from patient's records (see supplementary information).

Patients were retrospectively asked about breast cancer diagnosis journey events from their first initial symptom recognition to their first healthcare visit. Patients were encouraged to remember important time points such as the time when they recognize the first breast abnormalities, the time when they first visit healthcare. We tried to make the patients remember the dates in relation to known calendars like holidays, New Year, etc. The data collectors were four BSC nurses who are working in the oncology unit of selected hospitals since they know the study area very well and are expected to be honest and diligent, and willing to face difficulties that may arise during the process of interviewing. Two supervisors were recruited for supervising the data collectors in each of the selected hospitals.

Delayed diagnosis can be categorized into patient delay and provider delay or health system delay. The patient delay time was defined from a patient first becoming aware of symptoms until their first medical consultation and it was categorized as more than or equal to 3 months ( $\geq 90$ days): long patient delay, and less than 3 months ( $<90$ days): short patient delay. ${ }^{16,20,21}$

Information on tumor size $(\mathrm{T})$ and nodal status $(\mathrm{N})$ was used to derive stage by the American Joint Committee on Cancer staging system AJCC ( $7^{\text {th }}$ edition). All laboratory investigation and surgical findings were used to stage the disease. Stage 1 (T1N0); stage 2 (IIA=T0N1, T1N1, \& $\mathrm{T} 2 \mathrm{~N} 0, \mathrm{IIB}=\mathrm{T} 2 \mathrm{~N} 1, \& \mathrm{~T} 3 \mathrm{~N} 0)$, and stage 3 (IIIA=T0N2, $\mathrm{T} 1 \mathrm{~N} 2, \mathrm{~T} 2 \mathrm{~N} 2, \mathrm{~T} 3 \mathrm{~N} 1, \& \mathrm{~T} 3 \mathrm{~N} 2, \mathrm{IIIB}=\mathrm{T} 4 \mathrm{~N} 0, \mathrm{~T} 4 \mathrm{~N} 1, \mathrm{~T} 4 \mathrm{~N} 2$, $\mathrm{IIIC}=$ Ant TN3), and stage 4 (any $\mathrm{T}$, any N, and M1). ${ }^{23}$

Patients diagnosed with breast cancer stage III and IV were defined as advanced stages and patients diagnosed with breast cancer stage I and II were considered as early stages. $^{13,20}$

To assure the quality of the data, a structured and pretested questionnaire was used which was prepared in a simple and easily understandable language. One day training was given for data collectors and supervisors before data collection. Strict supervision and monitoring was done during data collection.

\section{Data Processing and Analysis Procedures}

Data was coded and entered using EPI info version 7.2 and exported to SPSS version 23 for further analysis. Before and during data processing the information was checked for completeness and internal consistency. It was verified that all the totals correspond to the total number of participants and checked by running simple frequencies in SPSS for all the variables.

The analyses were verified using descriptive interpretation for demographic, socio-economic and clinical characteristics of the study participants using frequencies and other summary statistics. Binary logistic regression was used to measure the association of each covariate with outcome variable. In addition, factors that were associated with outcome variable at $p$-value $<0.05$ significance level were included in the 
multivariable logistic regression analysis to control the potential confounders. The result of the final model was expressed in terms of Adjusted Odd Ratio (AOR) and 95\% confidence intervals (CI), and Statistical significance was declared at a $P$-value less than 0.05 .

\section{Ethical Consideration}

Ethical approval was obtained from the research ethics committee of Debre Tabor University. Following the endorsement by the research ethics committee, the selected hospitals were informed about the study through a Support letter. Concerned bodies in the selected hospitals were briefed about the study before the start of data collection. Informed verbal consent was obtained from study participants which was approved by the Research Ethics Committee of Debre Tabor University, and that this study was conducted in accordance with the Declaration of Helsinki. Confidentiality of information and privacy of participants' interview was respected.

\section{Results}

\section{Socio-Demographic Characteristics of Breast Cancer Patients}

A total of 371 breast cancer patients fulfilled the inclusion criteria and participated in the study. More than half $(288,77.6 \%)$ of the breast cancer patients were above 40 years. The median age of patients at diagnosis was 40 years (interquartile range $=30-70$ ). More than two thirds $(249,67.1 \%)$ of breast cancer patients were from rural residence. About 136 (36.7\%) of women were illiterate (Table 1).

\section{Clinical Characteristics of Breast Cancer Patients}

Among the breast cancer patients, the majority (209, $56.3 \%)$ were premenopausal women. About 74 (19.9\%) had a family history of breast cancer and $11(3 \%)$ patients were HIV positive. Among the patients, 142 (38.3\%) had a history of comorbidities. More than three quarters (328, $88.4 \%$ ) of breast cancer patients had a breast lump, and $161(43.4 \%)$ had a painful wound on the breast at presentation. The most common reasons mentioned for late presentation to the health facility were lack of awareness about early symptoms of breast cancer $(345,92.9 \%)$, use of traditional and spiritual treatment options $(286,77.1 \%)$, and financial problems for medical care and transport costs (217, 58.5\%) (Table 2).
Table I Socio-Demographic Characteristics of Breast Cancer Patients at Two Cancer Referral Centers in Northwest Ethiopia, 2020

\begin{tabular}{|c|c|c|}
\hline Characteristics & $\begin{array}{l}\text { Frequency } \\
(n=371)\end{array}$ & Percentage \\
\hline \multicolumn{3}{|l|}{ Age group } \\
\hline$<40$ & 83 & 22.4 \\
\hline$\geq 40$ & 288 & 77.6 \\
\hline Mean & 48.1 & \\
\hline \multicolumn{3}{|l|}{ Home residence } \\
\hline Rural & 249 & 67.1 \\
\hline Urban & 122 & 32.9 \\
\hline \multicolumn{3}{|l|}{ Marital status } \\
\hline Married & 298 & 80.3 \\
\hline Single & 73 & 19.7 \\
\hline \multicolumn{3}{|l|}{ Religion } \\
\hline Orthodox & 172 & 46.4 \\
\hline Muslim & 96 & 25.9 \\
\hline Protestant & 97 & 26.1 \\
\hline Catholic & 6 & 1.6 \\
\hline \multicolumn{3}{|l|}{ Educational status } \\
\hline Illiterate & 136 & 36.7 \\
\hline Primary education & 153 & 41.2 \\
\hline Secondary education and above & 82 & 22.1 \\
\hline \multicolumn{3}{|l|}{ Occupational status } \\
\hline Housewife & 215 & 58.0 \\
\hline Farmer & 94 & 25.3 \\
\hline Government employee & 52 & 14.0 \\
\hline Other & 10 & 2.7 \\
\hline \multicolumn{3}{|l|}{ Distance to the health facility } \\
\hline$<5 \mathrm{~km}$ & 163 & 43.9 \\
\hline$\geq 5 \mathrm{~km}$ & 208 & 56.1 \\
\hline
\end{tabular}

\section{Tumor Characteristics of Breast Cancer Patients}

More than two thirds $(320,86.3 \%)$ of the patients had presented with tumor which involved axillary lymph node. More than half $(209,56.3 \%)$ of the patients had a tumor size of more than $5 \mathrm{~cm}$. The mean $( \pm \mathrm{SD})$ tumor size at diagnosis was $6 \pm 4 \mathrm{~cm}$. Almost all patients $(347,93.5 \%)$ had invasive ductal carcinoma. Lobular carcinoma was found only on 18 (4.9\%) patients. The result showed that about 140 (45.6\%) patients had poorly differentiated invasive carcinoma (grade III tumor) and 128 (41.7\%) had moderately differentiated invasive carcinoma (grade II tumor) (Table 3). 
Table 2 Clinical Characteristics of Breast Cancer Patients at Two Cancer Referral Centers in Northwest Ethiopia, 2020

\begin{tabular}{|c|c|c|}
\hline Characteristics & $\begin{array}{l}\text { Frequency } \\
(n=371)\end{array}$ & Percentage \\
\hline \multicolumn{3}{|l|}{ Menopausal status } \\
\hline Pre-Menopausal & 209 & 56.3 \\
\hline Menopausal & 69 & 18.6 \\
\hline Post-Menopausal & 93 & 25.1 \\
\hline \multicolumn{3}{|l|}{ HIV status } \\
\hline Negative & 360 & 97.0 \\
\hline Positive & II & 3.0 \\
\hline \multicolumn{3}{|l|}{ Family history of breast cancer } \\
\hline Yes & 74 & 19.9 \\
\hline No & 297 & 80.1 \\
\hline \multicolumn{3}{|l|}{$\begin{array}{l}\text { History of any breast problem } \\
\text { before }\end{array}$} \\
\hline Yes & 138 & 37.2 \\
\hline No & 233 & 62.8 \\
\hline \multicolumn{3}{|l|}{ Practicing breast self-examination } \\
\hline Yes & 45 & 12.1 \\
\hline No & 326 & 87.9 \\
\hline \multicolumn{3}{|l|}{ History of any comorbidities } \\
\hline Yes & 142 & 38.3 \\
\hline No & 229 & 61.7 \\
\hline \multicolumn{3}{|l|}{ Use of traditional treatment } \\
\hline Yes & 256 & 69.0 \\
\hline No & 115 & 31.0 \\
\hline \multicolumn{3}{|l|}{ Presenting chief compliant } \\
\hline Breast lump or mass & 328 & 88.4 \\
\hline Swelling or lump in armpit & 38 & 10.2 \\
\hline Painful wound & 161 & 43.4 \\
\hline Other* & 12 & 3.2 \\
\hline \multicolumn{3}{|l|}{$\begin{array}{l}\text { Method of detection of } \\
\text { symptoms }\end{array}$} \\
\hline Accidentally & 248 & 66.8 \\
\hline During breast feeding & 57 & 15.4 \\
\hline During breast self-examination & 43 & 11.6 \\
\hline Other** & 23 & 6.2 \\
\hline \multicolumn{3}{|l|}{$\begin{array}{l}\text { Patient reason for late } \\
\text { presentation }\end{array}$} \\
\hline $\begin{array}{l}\text { Lack of awareness about early } \\
\text { symptoms }\end{array}$ & 345 & 92.9 \\
\hline $\begin{array}{l}\text { Relating symptoms with other } \\
\text { medical problems }\end{array}$ & 132 & 35.6 \\
\hline $\begin{array}{l}\text { Belief that breast cancer has not } \\
\text { any medical treatment }\end{array}$ & 88 & 23.7 \\
\hline $\begin{array}{l}\text { Use of traditional and spiritual } \\
\text { treatment options }\end{array}$ & 286 & 77.1 \\
\hline
\end{tabular}

(Continued)
Table 2 (Continued).

\begin{tabular}{|l|l|l|}
\hline Characteristics & $\begin{array}{l}\text { Frequency } \\
(\mathbf{n = 3 7 I )}\end{array}$ & Percentage \\
\hline Financial problems & 217 & 58.5 \\
Others*** & 35 & 9.4 \\
\hline
\end{tabular}

Notes: * nipple retraction, nipple discharge, skin color change;** when produce discharge, and pain; *** fear of surgery (loss of breast), lack of trust of HCP.

Table 3 Tumor Characteristics of Breast Cancer Patients at Two Cancer Referral Centers in Northwest Ethiopia, 2020

\begin{tabular}{|c|c|c|}
\hline Characteristics & Frequency & Percentage \\
\hline $\begin{array}{l}\text { Axillary lymph node status } \\
\text { Positive } \\
\text { Negative }\end{array}$ & $\begin{array}{l}320 \\
51\end{array}$ & $\begin{array}{l}86.3 \\
13.7\end{array}$ \\
\hline $\begin{array}{l}\text { Tumor metastases to other body } \\
\text { parts } \\
\text { Yes } \\
\text { No }\end{array}$ & $\begin{array}{l}53 \\
318\end{array}$ & $\begin{array}{l}14.3 \\
85.7\end{array}$ \\
\hline $\begin{array}{l}\text { Type of tumor } \\
\text { Ductal } \\
\text { Lobular } \\
\text { Other* }\end{array}$ & $\begin{array}{l}347 \\
18 \\
6\end{array}$ & $\begin{array}{l}93.5 \\
4.9 \\
1.6\end{array}$ \\
\hline $\begin{array}{l}\text { Tumor size in cm } \\
\leq 5 \mathrm{~cm} \\
>5 \mathrm{~cm} \\
\text { Median } \pm \mathrm{IQR}\end{array}$ & $\begin{array}{l}162 \\
209 \\
6.3 \pm 3.1 \mathrm{~cm}\end{array}$ & $\begin{array}{l}43.7 \\
56.3\end{array}$ \\
\hline $\begin{array}{l}\text { Tumor grade }(\mathbf{n}=\mathbf{3 0 7}) \\
\text { Grade I } \\
\text { Grade II } \\
\text { Grade III }\end{array}$ & $\begin{array}{l}39 \\
128 \\
140\end{array}$ & $\begin{array}{l}12.7 \\
41.7 \\
45.6\end{array}$ \\
\hline $\begin{array}{l}\text { Patient had taken any treatment } \\
\text { Yes } \\
\text { No }\end{array}$ & $\begin{array}{l}364 \\
7\end{array}$ & $\begin{array}{l}98.1 \\
1.9\end{array}$ \\
\hline $\begin{array}{l}\text { Type of treatment the patient } \\
\text { had taken } \\
\text { Surgery } \\
\text { Chemotherapy } \\
\text { Hormonal therapy } \\
\text { Other** }\end{array}$ & $\begin{array}{l}357 \\
163 \\
50 \\
4\end{array}$ & $\begin{array}{l}96.2 \\
43.9 \\
13.5 \\
1.1\end{array}$ \\
\hline
\end{tabular}

Notes: * mixed tumors and inflammatory carcinoma's. ** radiotherapy and other systemic treatments for underlying disease.

Abbreviation: IQR, interquartile range.

\section{Breast Cancer Patients' Medical Care Pathway}

A total of $281(75.7 \%)$ breast cancer patients had long patient delay $\geq 90$ days ( 3 months). The average patient delay time 
was 8 months, with a range of 2 weeks to 3 years. A significantly higher proportion $(211,79.9 \%)$ of patients who were diagnosed at late stage (stage II\&IV) had long patient delay of more than 3 months $(P=0.0003)$. The larger proportion $(191,66.3 \%$ ) of patients who were age $\geq 40$ years had longer patient delay as compared with those less than 40 years old $(40,48.2 \%)(P=0.015)$. A higher proportion (234, $75.5 \%$ ) of married women had significantly longer presentation delay to present to a health facility $(P=0.007)$. A significantly large proportion $(113,83.1 \%)$ of illiterate women had longer patient delay than those who had primary $(107,69.9 \%)$ and secondary and above educational levels $(61,74.4 \%)(P<0.001)$.

Women who did not have history of any breast problem before $(190,81.5 \%)$ had longer patient delay than their counterparts $(91,65.9 \%)(P=0.0004)$. The majority of women $(185,88.9 \%)$ who travel more than $5 \mathrm{~km}$ distance to arrive at the nearby health facility had longer patient delay than who travel less than $5 \mathrm{~km}(96,58.9 \%)$ $(P<0.001)$ (Table 4).

\section{Stage at Diagnosis of Breast Cancer Patients}

Out of 371 breast cancer patients who participated in this study; the overall magnitude of late stage diagnosis was 71.2\% (95\% CI=67.5-77.1\%). Among these, 211 (56.9\%) patients were diagnosed at stage III and the remaining 53 $(14.3 \%)$ were stage IV at diagnosis. Stage I and II accounts for $37(9.9 \%)$ and $70(18.9 \%)$ of the breast cancer patients.

\section{Predictors of Patient Delay Among Breast Cancer Patients}

Patients who were from rural residence were 3.7-times more likely to delay to presentation (patient delay) than urban residence $(\mathrm{AOR}=3.72 ; \quad 95 \% \quad \mathrm{CI}=1.82-7.61)$. Illiterate women were approximately 3.8-times more likely to be delayed at presentation than those who had secondary educational level and above (AOR $=3.8 ; 95 \%$ $\mathrm{CI}=1.71-8.64)$.

Patients who had presented with a painless wound were approximately 3.3-times more likely to be presented late than patients who had a painful wound at presentation $(\mathrm{AOR}=3.32$; 95\% CI=1.93-5.72). A travel distance to the nearby health facility $\geq 5 \mathrm{~km}$ was also associated with late presentation of patients with breast cancer $(\mathrm{AOR}=1.66 ; 95 \% \mathrm{CI}=1.09-3.00)$.

Breast cancer patients who had swelling or a lump in armpit were less likely to delay than their counterparts.
Women who did not have any lump/swelling in their armpit were 6-times more likely to present late to medical care for breast cancer symptoms $\quad(\mathrm{AOR}=6.16 ; 95 \%$ $\mathrm{CI}=2.80-13.54)$. In addition, women who had a history of any breast problem before were less likely to present late to the health facility, while women who did not have any breast problem before were more likely to delay for medical care $(\mathrm{AOR}=2.46 ; 95 \% \mathrm{CI}=1.43-4.22)$ (Table 5).

\section{Discussion}

Patient delay's in presentation and advanced stage at diagnosis has been widely reported and significantly affects breast cancer survival worldwide. Most breast cancer patients in low-income countries mainly in Africa suffer very long delays and are diagnosed at advanced stages and have lower survival rates. ${ }^{24-26}$ Evidence has shown that delay in presentation is a significant contributor for progression of the disease to advanced stage, consequently increasing mortality from breast cancer. ${ }^{13,15,20,27,28}$

We tried to assess the patient delay in presentation and the factors contributing to it among breast cancer patients at two oncology referral centers in the Northwest part of Ethiopia. We found long patient delay (delay to presentation of more than 3 month) of $75.7 \%$ with a $95 \%$ CI of $71.5-80.2 \%$, with the average patient delay time of 8 months. The patient delay time to presentation ranged from 2 weeks to 36 months. This finding is in line with study findings from sub-Saharan Africa, ${ }^{15}$ Rwanda, ${ }^{20}$ Senegal (78.4\%), ${ }^{27}$ and a meta-analysis in Africa $(54 \%) .{ }^{17}$ However it is much higher than a multinational analysis survey finding in which the average patient delay time was 4.7 weeks, and a finding in China in which the range of patient delay was $0.2-900$ days. ${ }^{16,29}$ The difference might be due to socioeconomic and other development differences between the countries since Ethiopia is a low-income country and with poor health infrastructure and low awareness of people about non-communicable disease including cancer. ${ }^{19}$

Our study revealed that the majority $(264,71.2 \%)$ of breast cancer patients were presented at advanced stage of the disease which is higher than late stage breast cancer report in Libya $(65.5 \%),{ }^{21}$ Nigeria $(67.3 \%),{ }^{12}$ and Egypt $(46 \%),{ }^{30}$ however the finding is lower than studies conducted in South Africa $(85 \%),{ }^{11}$ Senegal $(81.7 \%),{ }^{27}$ Rwanda $(76 \%),{ }^{20}$ and in North-western Tanzania $(84.4 \%){ }^{31}$ The observed variation might be due to differences in staging system and some other sociocultural and infrastructure differences. In the 
Table 4 Association Between Socio-Demographic and Clinical Characteristics with Patient Delay at Two Cancer Referral Centers in Northwest Ethiopia, 2020

\begin{tabular}{|c|c|c|c|c|c|}
\hline \multirow[t]{2}{*}{ Characteristics } & \multirow[t]{2}{*}{ Frequency (n, \%) } & \multicolumn{2}{|c|}{ Patient Delay } & \multirow[t]{2}{*}{$\chi^{2}$} & \multirow[t]{2}{*}{$P$-value } \\
\hline & & $\geq 3$ Months & $<3$ Months & & \\
\hline \multicolumn{6}{|l|}{ Age group } \\
\hline$<40$ & 83 & 40 (48.2\%) & $43(51.8 \%)$ & 9.0 & $0.015^{*}$ \\
\hline$\geq 40$ & 288 & 191 (66.3\%) & 97 (33.7\%) & & \\
\hline \multicolumn{6}{|l|}{ Home residence } \\
\hline Rural & 249 & $217(87.2 \%)$ & $32(12.8 \%)$ & 53 & $<0.001 *$ \\
\hline Urban & 122 & $64(52.5 \%)$ & $58(47.5 \%)$ & & \\
\hline \multicolumn{6}{|l|}{ Marital status } \\
\hline Married & 298 & $234(75.5 \%)$ & $64(21.5 \%)$ & 6.3 & $0.007^{*}$ \\
\hline Single & 73 & 47 (64.4\%) & $26(35.6 \%)$ & & \\
\hline \multicolumn{6}{|l|}{ Educational status } \\
\hline Illiterate & 136 & $113(83.1 \%)$ & $23(196.9 \%)$ & 23.6 & $<0.00 I^{*}$ \\
\hline Primary education & 153 & $107(69.9 \%)$ & $46(30.1 \%)$ & & \\
\hline Secondary education and above & 82 & 61 (74.4\%) & $21(25.6 \%)$ & & \\
\hline \multicolumn{6}{|l|}{ Travel distance } \\
\hline$<5 \mathrm{~km}$ & 163 & $96(58.9 \%)$ & $67(41.1 \%)$ & 44.9 & $<0.001 *$ \\
\hline$\geq 5 \mathrm{~km}$ & 208 & $185(88.9 \%)$ & $23(11.1 \%)$ & & \\
\hline \multicolumn{6}{|l|}{ Family history of breast cancer } \\
\hline Yes & 74 & $51(68.9 \%)$ & $23(31.1 \%)$ & 2.3 & 0.126 \\
\hline No & 297 & $230(77.4 \%)$ & $67(22.6 \%)$ & & \\
\hline \multicolumn{6}{|l|}{ Painful breast ulcer or wound } \\
\hline Yes & 161 & $104(64.6 \%)$ & 57 (35.4\%) & 19.2 & $<0.001 *$ \\
\hline No & 210 & 177 (84.3\%) & $33(15.7 \%)$ & & \\
\hline \multicolumn{6}{|l|}{ History of any comorbidities } \\
\hline Yes & 142 & $76(53.5 \%)$ & $66(46.5 \%)$ & 61.8 & $<0.001 *$ \\
\hline No & 229 & 205 (89.5\%) & $24(10.5 \%)$ & & \\
\hline \multicolumn{6}{|c|}{ History of any breast problem before } \\
\hline Yes & 138 & 91 (65.9\%) & $47(34.1 \%)$ & 11.5 & $0.0004 *$ \\
\hline No & 233 & $190(81.5 \%)$ & $43(18.5 \%)$ & & \\
\hline \multicolumn{6}{|l|}{ Swelling/lump in armpit } \\
\hline Yes & 38 & 17 (44.7\%) & 21 (55.3\%) & 22 & $<0.001 *$ \\
\hline No & 333 & 264 (79.3\%) & $69(20.7 \%)$ & & \\
\hline \multicolumn{6}{|l|}{ Stage at diagnosis } \\
\hline Early stage (I\&II) & 107 & $70(65.4 \%)$ & 37 (34.6\%) & 8.7 & $0.0003^{*}$ \\
\hline Late stage (II\&IV) & 264 & $211(79.9 \%)$ & $53(20.1 \%)$ & & \\
\hline
\end{tabular}

Notes: $*$ statistical significant association, $\chi^{2}=$ chi-square test.

study among the patients diagnosed at advanced stage, the majority $(211,79.9 \%)$ of patients had a delay of more than 3 months. Long patient delays were significantly associated with an advanced stages of the disease $(P=0.0003)$. This finding is similar to a study conducted in Iran, in which among patients diagnosed at late stage, the majority had more than 3 months delay and a delay of more than 3 month was a significant predictors of late stage diagnosis. ${ }^{32} \mathrm{~A}$ similar study in India showed that the odds of late stage disease were almost 3.5-times more with patient delay of more than 3 months. ${ }^{33}$ This might be because the delay time will give a longer time for progression and growth of the disease to advanced stage. 
Table 5 Multivariable Logistic Regression Analysis of Factors Associated with Patient Delay of Breast Cancer at Two Cancer Referral Centers in Northwest Ethiopia, 2020

\begin{tabular}{|c|c|c|c|c|c|}
\hline \multirow[t]{2}{*}{ Characteristics } & \multicolumn{2}{|c|}{ Patient delay } & \multirow[t]{2}{*}{ Crude OR with $95 \% \mathrm{CI}$} & \multirow[t]{2}{*}{ Adjusted OR with $95 \% \mathrm{Cl}$} & \multirow[t]{2}{*}{$P$-value } \\
\hline & $\geq 3$ Months & $<3$ Months & & & \\
\hline $\begin{array}{l}\text { Age group } \\
\quad<40 \\
\geq 40\end{array}$ & $\begin{array}{l}40(48.2 \%) \\
191(66.3 \%)\end{array}$ & $\begin{array}{l}43(51.8 \%) \\
97(33.7 \%)\end{array}$ & $\begin{array}{l}\text { I } \\
2.12(1.29-3.47)\end{array}$ & $\begin{array}{l}\text { I } \\
1.16(0.638-2.09)\end{array}$ & 0.634 \\
\hline $\begin{array}{l}\text { Home residence } \\
\text { Rural } \\
\text { Urban }\end{array}$ & $\begin{array}{l}217(87.2 \%) \\
64(52.5 \%)\end{array}$ & $\begin{array}{l}32(12.8 \%) \\
58(47.5 \%)\end{array}$ & $\begin{array}{l}6.1(3.67-10.27) \\
1\end{array}$ & $\begin{array}{l}3.72(1.82-7.6 \mid) \\
\mid\end{array}$ & $<0.00 I^{*}$ \\
\hline $\begin{array}{l}\text { Marital status } \\
\text { Married } \\
\text { Single }\end{array}$ & $\begin{array}{l}234(75.5 \%) \\
47(64.4 \%)\end{array}$ & $\begin{array}{l}64(21.5 \%) \\
26(35.6 \%)\end{array}$ & $2.02(1.16-3.52)$ & $\begin{array}{l}1.38(0.66-2.91) \\
\mathrm{I}\end{array}$ & 0.395 \\
\hline $\begin{array}{l}\text { Comorbidities } \\
\text { Yes } \\
\text { No }\end{array}$ & $\begin{array}{l}76(53.5 \%) \\
205(89.5 \%)\end{array}$ & $\begin{array}{l}66(46.5 \%) \\
24(10.5 \%)\end{array}$ & $7.4(4.33-12.68)$ & I. II (0.59-2.07) & 0.734 \\
\hline $\begin{array}{l}\text { Educational status } \\
\text { Illiterate } \\
\text { Primary education } \\
\text { Secondary education and above }\end{array}$ & $\begin{array}{l}113(83.1 \%) \\
107(69.9 \%) \\
61(74.4 \%)\end{array}$ & $\begin{array}{l}23(196.9 \%) \\
46(30.1 \%) \\
21(25.6 \%)\end{array}$ & $\begin{array}{l}1.69(1.06-3.30)^{*} \\
0.80(0.44-1.47) \\
I\end{array}$ & $\begin{array}{l}3.8(1.71-8.64) \\
0.96(0.93-4.14) \\
1\end{array}$ & $\begin{array}{l}0.001 * \\
0.079\end{array}$ \\
\hline $\begin{array}{l}\text { Painful breast ulcer or wound } \\
\text { Yes } \\
\text { No }\end{array}$ & $\begin{array}{l}104(64.6 \%) \\
177(84.3 \%)\end{array}$ & $\begin{array}{l}57(35.4 \%) \\
33(15.7 \%)\end{array}$ & $2.94(I .79-4.8 I)$ & $3.32(1.93-5.72)$ & $<0.00 I^{*}$ \\
\hline $\begin{array}{l}\text { Distance to the nearby health facility } \\
<5 \mathrm{~km} \\
\geq 5 \mathrm{~km}\end{array}$ & $\begin{array}{l}96(58.9 \%) \\
185(88.9 \%)\end{array}$ & $\begin{array}{l}67(41.1 \%) \\
23(11.1 \%)\end{array}$ & $\begin{array}{l}\text { I } \\
5.61 \text { (3.29-9.58) }\end{array}$ & $1.66(1.09-3.00)$ & $0.0093 *$ \\
\hline $\begin{array}{l}\text { Swelling or lump in armpit } \\
\text { Yes } \\
\text { No }\end{array}$ & $\begin{array}{l}17(44.7 \%) \\
264(79.3 \%)\end{array}$ & $\begin{array}{l}21(55.3 \%) \\
69(20.7 \%)\end{array}$ & $\begin{array}{l}\text { I } \\
4.73(2.37-9.44)\end{array}$ & $6.16(2.80-13.54)$ & $<0.00 I^{*}$ \\
\hline $\begin{array}{l}\text { History of any breast problem before } \\
\text { Yes } \\
\text { No }\end{array}$ & $\begin{array}{l}91(65.9 \%) \\
190(81.5 \%)\end{array}$ & $\begin{array}{l}47(34.1 \%) \\
43(18.5 \%)\end{array}$ & $\begin{array}{l}\text { I } \\
2.28(1.4 \mid-3.70)\end{array}$ & $2.46(1.43-.22)$ & $0.001 *$ \\
\hline
\end{tabular}

Notes: *Istatistically significant association.

Abbreviation: OR, odds ratio.

Our study showed that the most common reasons mentioned for late presentation to a health facility were lack of awareness about early symptoms of breast cancer (345, $92.9 \%$ ), use of traditional and spiritual treatment options (286, 77.1\%), financial problems for medical care and transport costs $(217,58.5 \%)$, relating early symptoms with other medical problems $(132,35.6 \%)$, belief that breast cancer has not any medical treatments $(88,23.7 \%)$, fear of surgery (loss of breast), and lack of trust on HCP (35, 9.4\%). These reasons were reported in other similar studies in which low economic status, lack of access to medical care, anxiety, fear of mastectomy, the necessity to prioritize the immediate needs of daily life, non-disclosure of the situation, hoping the wound will would resolve soon, low education, low level of awareness, religious beliefs, preference for alternative care, and social influence were the factors mentioned for delay presentation. ${ }^{15-17}$

In our study the multivariable analysis showed that a travel distance to the nearby health facility $\geq 5 \mathrm{~km}$, being from rural residence, having no history of any breast problem before, having no history of any lump or swelling in the armpit, painless lump in the breast, and being illiterate were important significant predictors of long patient delay. 
Women who were from rural areas were 4-times more likely to have delay to presentation (patient delay) than women from an urban residence. This finding is also similar to studies in which women from rural area were presented late to medical care compared with women from urban areas. ${ }^{15,17,20,34,35}$

Women who traveled $\geq 5 \mathrm{~km}$ to get to the nearby health facility were also 1.6-times more likely to have a long delay in presentation than their counterparts. This can be explained as the long distance traveling to get primary healthcare units and cancer diagnostic centers makes the patients delay in seeking early medical care since women who live far from health facilities will face difficulty of getting transportation access.

Breast cancer awareness and knowledge of the importance of early detection and diagnosis are poor in subSaharan African countries. ${ }^{13,34}$ Similarly in our study illiterate women were " 2.5 -times more likely to be delayed at presentation than had secondary educational level and above. This finding is similar to other studies conducted in different countries. ${ }^{20,21}$ This could be explained as illiterate women were able to read materials like brochures, leaflets, etc. which would increase their general knowledge on breast cancer risks, early symptoms, and treatment options which in turn makes them have low awareness about the disease; as a result, their medical care-seeking behavior will be low.

The study shows that patients who had presented with painless breast wound were "3.3-times more likely to present late than patients who had a painful wound at presentation. This is due to the way in which individuals interpret and label their symptoms which possibly influence their early medical seeking behavior, unless the symptoms become painful and severe. This finding is also similarly reported in Egypt and in other sub-Saharan African countries in which women without any pain were more likely to present late than those having pain as the first symptom. ${ }^{15,30}$

Breast cancer patients who had swelling or a lump in the armpit were less likely to be delayed than their counterparts. Women who did not have any lump/swelling in their armpit were 6-times more likely to present late to medical care for breast cancer symptoms. In addition women who had a history of any breast problem before were less likely to present late to the health facility, while women who did not have any breast problem before were more likely to delay in seeking early medical care. This finding is similar to another study finding in which a negative family history of breast cancer was associated with presentation delay. ${ }^{27}$ Other similar studies also reported that women who had a previous history of benign breast disease, other co-morbidities, personnel and family history of breast cancer are less likely to delay than their counterparts. ${ }^{35,36}$ The possible explanation might be people may relate their early symptoms to other usual benign health condition, or they may consider it as a self-limited illness unless the symptoms become large and negatively affect their daily lives. On the other hand, individuals who have personal or family history of any of similar comorbidities will have a need to get early medical seeking due to fear of the conditions and are more likely to visit a health facility early for their underlying medical problems.

Studies also showed that knowledge of breast selfexamination increased the likelihood of women to present early for breast cancer care and be diagnosed at early stages. ${ }^{16,17,30}$ Similarly women who were able to perform breast self-exam were diagnosed earlier compared with others. ${ }^{34}$ However, in our study the majority $(87.9 \%)$ of the women did not practice breast selfexamination, and most $(66.8 \%)$ of them detected their breast abnormalities accidentally when they were washing their body, during sleeping, or when they took off their clothes, and some others (15.4\%) detected it when they were breast feeding and when the disease produced discharge and pain (6.9\%). Only $11.6 \%$ of women detected the abnormalities on their breast by breast self-examination. Similarly, $68 \%$ of breast cancer patients in Libya noted lumps as an accidental finding, while four (2\%) patients detected lump(s) during breast self-examination. ${ }^{21}$

\section{Strength and Limitation of the Study}

Our study is the first study conducted in the Northwestern part of Ethiopia at the only two oncology centers to determine the magnitude of patient delay and the predictors among breast cancer patients, and we involve all newly diagnosed breast cancer patients diagnosed in the study period, which will increase its representativeness. In addition, the hospitals are the only referral centers for all cancer patients in the Northern western region of Ethiopia, so the possibility of getting almost all cases in the region is high. However, due to the cross-sectional nature of the study, the study could not show a cause and effect relationship and recall bias is a potential treat for our study, since patients have difficulties to remember the 
exact date of their early symptom recognition and other important time points in their diagnostic journey.

\section{Conclusion}

In conclusion, long patient delay and advanced stage diagnosis are major findings in our study. Travel distance $\geq 5 \mathrm{~km}$, being from a rural residence, having no history of any breast problem before, having no history of any lump or swelling in the armpit, painless lump in the breast, and being illiterate were important significant predictors of long patient delay for breast cancer patients in Northwestern Ethiopia. Therefore, public awareness programs about breast cancer should be designed to prevent patient delay in presentation and to promote early detection of cases before advancement.

\section{Abbreviations}

FMOH, Federal Ministry of Health; HCP, healthcare provider; IQR, interquartile range; LMICs, low- and middleincome countries; SD, standard deviation, SPSS, Statistical Package for Social Sciences.

\section{Data Sharing Statement}

The data for this study will be obtained from the corresponding author upon reasonable request.

\section{Ethics Approval and Consent to Participate}

Ethical approval was obtained from the research ethics committee of Debre Tabor University. Following the endorsement by the research ethics committee, the selected hospitals were informed about the study through a Support letter. Concerned bodies in the selected hospitals were briefed about the study before the start of data collection. Informed verbal consent was obtained from study participants, which was approved by the Research Ethics Committee of Debre Tabor University, and this study was conducted in accordance with the Declaration of Helsinki. Confidentiality of information and privacy of participants' interview was respected.

\section{Acknowledgment}

We are grateful for the cooperation of each of the hospital oncology unit staffs, data collectors, and patients for their co-operation during data collection.

\section{Author Contributions}

All authors made significant contributions to the conception and design, acquisition of data, or analysis and interpretation of data; they also took part in drafting the manuscript and agreed on the journal to which the article has been submitted. All authors approved the final version of the manuscript to be published; and agree to be accountable for all aspects of the work.

\section{Disclosure}

The authors report no conflicts of interest for this work.

\section{References}

1. WHO. Cancer fact sheet, 2018.http://www.who.int/en/. Accessed September 9, 2020.

2. American Cancer Society. Breast Cancer Facts \& Figures 2019-2020. Atlanta: American Cancer Society, Inc; 2019.

3. Azubuike SO, Muirhead C, Hayes L, McNally R. Rising global burden of breast cancer: the case of sub-Saharan Africa (with emphasis on Nigeria) and implications for regional development: a review. World J Surg Oncol. 2018;16(1):63. doi:10.1186/s12957-018-1345-2

4. Boyle PAP, Adebamowo C, et al. World Breast Cancer Report. Lyon: International Prevention Research Institute; 2012.

5. Addis Ababa City Population Based Cancer Registry Report. Addis Ababa, Ethiopia; 2014.

6. Memirie ST, Habtemariam MK, Asefa M, et al. Estimates of Cancer Incidence in Ethiopia in 2015 Using Population-Based Registry Data. J Global Oncol. 2018;4(4):1-11. doi:10.1200/JGO.17.00175

7. Andrew Donkor Fenlon Y, Opoku JL, Wiafe S. Factors Contributing to Late Presentation of Breast Cancer in Africa: a Systematic Literature Review. Arch Med. 2015;8(2):125.

8. Hiom SC. Diagnosing cancer earlier: reviewing the evidence for improving cancer survival. Br J Cancer. 2015;112(Suppl S1):S1S5. doi:10.1038/bjc.2015.23

9. Anderson BO, Cazap E, El Saghir NS, et al. Optimisation of breast cancer management in low-resource and middle-resource countries: executive summary of the Breast Health Global Initiative consensus, 2010. Lancet Oncol. 2011;12(4):387-398. doi:10.1016/S14702045(11)70031-6

10. Unger-Saldana $\mathrm{K}$. Challenges to the early diagnosis and treatment of breast cancer in developing countries. World J Clin Oncol. 2014;5 (3):465-477. doi:10.5306/wjco.v5.i3.465

11. Rayne S, Schnippel K, Grover S, Kruger D, Benn C, Firnhaber C. The effect of beliefs about breast cancer on stage and delay to presentation: results from a prospective study in urban South Africa. Afr J Surg. 2019;57(1). doi:10.17159/2078-5151/2018/v56n2a2704

12. Umoke IC, Garba ES. Breast cancer in North-Central Nigeria: challenges to good management outcome. Int Surg J. 2019;6 (9):3105-3110. doi:10.18203/2349-2902.isj20194042

13. Jedy-Agba E, McCormack V, Adebamowo C, et al. Stage at diagnosis of breast cancer in sub-Saharan Africa: a systematic review and meta-analysis. Lancet Global Health. 2016;4(12):e923-e935. doi:10.1016/S2214-109X(16)30259-5

14. Donkor A. Factors Contributing to Late Presentation of Breast Cancer in Africa: A Systematic Literature Review. Arch Med. 2015;8:2.

15. Espina C, McKenzie F, dos-Santos-Silva I. Delayed present ation and diagnosis of breast cancer in African women: a systematic review. Ann Epidemiol. 2017;27(10):e671. doi:10.1016/j.annepidem.2017.09.007

16. Zhang H, Wang G, Zhang J, Lu Y, Jiang X. Patient delay and associated factors among Chinese women with breast cancer. Medicine. 2019;40(e17454):98.

17. Olayide S. A godirin, Isiaka Aremu, Ganiyu A. Rahman.Prevalence of Themes Linked to Delayed Presentation of Breast Cancer in Africa: A Meta-Analysis of Patient-Reported Studies. JCO G Lobal Oncol. 2020;6:731-742. 
18. Abate SM, Yilma Z, Assefa M, Tigeneh W. Trends of Breast Cancer in Ethiopia. Int J Cancer Res Mol Mech. 2016;2(1):12.

19. FMOH. National Cancer Control Plan (2016-2020). Disease Prevention and Control Directorate. Addis Ababa, Ethiopia: Federal Ministry of Health; 2015.

20. Pace EL, Tharcisse MT, Hategekimana V. Delays in Breast Cancer Presentation and Diagnosis at Two Rural Cancer Referral Centers in Rwanda. Oncologist. 2015;20(7):780-788. doi:10.1634/theoncologist.2014-0493

21. Ermiah E, Abdalla F, Buhmeida A, Larbesh E, Pyrhönen S, Collan Y. Diagnosis delay in Libyan female breast cancer. BMC Res Notes. 2012;5(1):452. doi:10.1186/1756-0500-5-452

22. Benbakhta B, Tazi M, Benjaafar N, Khattabi A, Maaroufi A. Determinants of patient and health system delays for women with breast cancer in Morocco. BMJ. 2015;63(3):191-201.

23. Edge SB, Byrd DR, Compton CC, et al. AJCC Cancer Staging Manual. 7th ed. New York: Springer; 2009:419-460.

24. Gebremariam A, Addissie A, Worku A, et al. Time intervals experienced between first symptom recognition and pathologic diagnosis of breast cancer in Addis Ababa, Ethiopia: a cross-sectional study. BMJ Open. 2019;9(11):e032228. doi:10.1136/bmjopen-2019-032228

25. Eber-Schulz P, Tariku W, Reibold C, et al. Survival of breast cancer patients in rural Ethiopia. Breast Cancer Res Treat. 2018;170 (1):111-118. doi:10.1007/s10549-018-4724-z

26. Jedy-Agba E, McCormack V, Olaomi O, et al. Determinants of stage at diagnosis of breast cancer in Nigerian women: sociodemographic, breast cancer awareness, health care access and clinical factors. Cancer Causes Control. 2017;28(7):685-697. doi:10.1007/s10552-017-0894-y

27. Gueye M, Gueye SMK, Diallo M, et al. Sociodemographic Factors Associated with Delays in Breast Cancer. Open J Obstetrics Gynecol. 2017;07(04):455-463. doi:10.4236/ojog.2017.74047

28. Rayne S, Schnippel K, Kruger D, Benn A, Firnhaber C. Delay to diagnosis and breast cancer stage in an urban South African breast clinic. S Afr Med J. 2019;109(3):159-163. doi:10.7196/SAMJ.2019.v109i3.13283
29. Jassem J, Ozmen V, Bacanu F, et al. Delays in diagnosis and treatment of breast cancer: a multinational analysis. Eur J Public Health. 2013;24(5):761-767.

30. Mousa SM, Seifeldin IA, Hablas A, et al. Patterns of seeking medical care among Egyptian breast cancer patients: relationship to late-stage presentation. The Breast. 2011;20(6):555-561. doi:10.1016/j. breast.2011.07.001

31. Mabula BO, Mchembe DM, Chalya LP, et al. Stage at diagnosis, clinic pathological and treatment patterns of breast cancer at Bugando Medical Centre in North-western Tanzania. Tanzan J Health Res. 2012;14:4.

32. Iraj Harirchi MK, Hadi F, Madani SS, et al. Patient Delay, Diagnosis Delay and Treatment Delay for Breast Cancer: comparison of the Pattern between Patients in Public and Private Health Sectors. Arch Breast Cancer. 2015;2(2):52-57.

33. Gangane N, Nawi N, Hurtig KA, et al. Prevalence and Risk Factors for Patient Delay Among Women With Breast Cancer in Rural India. Asia Pacific J Public Health. 2016;28(1):72-82. doi:10.1177/ 1010539515620630

34. Akuoko CP, Armah E, Sarpong T, et al. Barriers to early presentation and diagnosis of breast cancer among African women living in sub-Saharan Africa. PLoS One. 2017;12(2):e0171024. doi:10.1371/ journal.pone. 0171024

35. Dickens C, Je M, Jacobson J, et al. Stage at breast cancer diagnosis and distance from diagnostic hospital in a periurban setting: a South African public hospital case series of over 1000 women. Int J Cancer. 2014;135(9):2173-2182. doi:10.1002/ijc.28861

36. Partridge H, Melissa E, Hughes A, et al. The Effect of Age on Delay in Diagnosis and Stage of Breast Cancer. Oncologist. 2012;17 (6):775-782. doi:10.1634/theoncologist.2011-0469
Journal of Multidisciplinary Healthcare

\section{Publish your work in this journal}

The Journal of Multidisciplinary Healthcare is an international, peerreviewed open-access journal that aims to represent and publish research in healthcare areas delivered by practitioners of different disciplines. This includes studies and reviews conducted by multidisciplinary teams as well as research which evaluates the results or conduct of such teams or healthcare processes in general. The journal covers a very wide range of areas and welcomes submissions from practitioners at all levels, from all over the world. The manuscript management system is completely online and includes a very quick and fair peer-review system. Visit http://www.dovepress.com/testimonials. php to read real quotes from published authors. 